\title{
Repair Work
}

\author{
DANA SIMMONS \\ UNIVERSITY OF CALIFORNIA, RIVERSIDE
}

\begin{abstract}
Fresh anxieties and new debts, in response to Jill Morawski's and Michelle Murphy's commentaries.
\end{abstract}

\section{Keywords}

reparative history; psychology; achievement; reassemblies

\section{Introduction}

"Here we are together, reading this essay, studying the cruelties of neoliberal academia" (Murphy 2016, 129). I am deeply grateful to be here, together, with Michelle Murphy and Jill Morawski.

Together with Murphy, I wonder how to dwell in already broken worlds. Murphy makes us think about the politically generative potential of anger, fear and pessimism. Together with Morawski, I worry that critique sometimes ends up reproducing its object. When social inequities get internalized, matters of the outside world get relocated inside the head. Critique itself can end up ingesting the modernizing totalities that it was meant to oppose. Morawski asks, "then what?" What happens next? (Morawski 2016, 134).

Morawski imagines readers of this journal becoming aware of "their own affect residues that emerge when they have tried on or internalized a psychological category." Affect residues. A beautiful term, which alerts us to look for things left over, for the supplements, stains and strains at the edges of high achievement worlds. Morawski tells us, "we need to attend to the

‘ Dana Simmons, Email: dana.simmons@ucr.edu

Copyright ( 2016 (Dana Simmons). Licensed under the Creative Commons Attribution Non-commercial No Derivatives (by-nc-nd). Available at estsjournal.org. 
remainders, the other ontological models and their fates" (135). My response is a kind of leftover, spilling out of gratitude to Murphy and Morawski and out of "fresh anxieties" over the nature of my project.

\section{Affect Residues}

Some notes on affect: I am anxious (no surprise there). I care about this and I don't want to mess it up. How might I offer an adequate, effective, competent response to these luminous comments? I hope to be adequate to their generosity. Adequacy is a strange yet very familiar frame for thinking about scholarly and friendly exchange, as though a measuring stick marks out the quality and equivalence of each contribution. I need to be deserving of these marvels. Like a potlatch, I hope my return offering may be as competent, effective, bright and meaningful as the original gifts. Adequacy speaks a language of gifts and debts.

These words-adequate, effective, competent-serve as performance metrics. They speak of being up to the task, capable of solving the problem. Here these performance metrics fold back and reproduce themselves within the very work of thinking about them: Am I up to the job of rethinking adequacy? Critique itself becomes a form of achievement. This piece of writing is a product, which will serve to meet my institution's productivity metrics and perhaps obtain a small pay raise. It is a personal working-out of my place in the academy. It is an attempt to make an offering to other scholars. It is an invitation to dialogue, to bring inner lives into a collective and collaborative project. How can one piece of writing-or one writer, for that matter--perform these doubling and perhaps contradictory achievements?

One more note: I am exhausted. Exhaustion is an achievement-oriented affect; I'm just too tired to do this well enough. Exhaustion is both retrospective and anticipatory. Looking backward, exhaustion comes with folding the task at hand into a legacy of past interactions, disappointments, unmet hopes, loneliness and estrangements. Looking forward, exhaustion comes with calculating the future costs and dangers of the task at hand. What have I done wrong that I'm not aware of yet?

Exhaustion is characteristic of the paranoid stance, turned reflexively upon the self. This is the affect residue of a state of non-innocence, knowing that everything I do, the cures and attempts to repair, may well also perpetuate damage. Exhaustion leads to constant doubt and anticipatory guilt. (In this sense, it feels a lot like parenting.) I ask, what damage am I perpetuating today?

\section{Unwieldy Reflexivity}

Morawski makes a critical point about critique itself perpetuating damage. When does a cure reproduce what it is meant to fix? When does a critique reproduce the object of its criticism?

"Reparative histories," Morawski writes, "are entangled with the very modern psychology they aim to supplant." This attempt at reparative history suffers from "reliance upon the very science that is being submitted to critical reflection" (136). It is, like most histories of 
psychology, a participant-observer story. It takes up the psychological language of affects to understand an experience and a history of affect. Historians, too, "mobilize certain conceptions of subjectivity." This problem even spills beyond the bounds of an academic history of psychology, for the world all around us is "thoroughly psychologized" (137). Morawski poses a vitally important question: How to carry out a responsible scholarly practice, when that practice is entangled in its own history? Unwieldy reflexivity, indeed.

The risk in writing a history of modernizing psychologists is that it ends up reproducing the modernizers' dominant position in and outside of academia. "A ...serious, undesired outcome is that certain psychological accounts of history will prevail, and these successor chronicles are likely to be fashioned with scientifically and culturally dominant explanations" (137). To do so misses the chance to consider alternative pathways, "research efforts that aspired to change social practices." A narrative of dominant psychologies effaces the tenuous existence of "other ontological models" (135).

Morawski identifies a system-level problem: critique can ingest and reassemble dominant modes of thinking and being. The figures of reassembly and repair allow for a fantasy of tinkering in a back room, away from scrutiny and insulated from effects on others. Nothing to see here but some minor modifications! This could be dangerous. Could repair end up rebuilding what it was designed to take apart? Who decides where to cut and orient and stick things back together?

\section{Debts}

This project began as a debt to an accomplished scholar, whom I met when she visited my campus and offered her work in the form of a job talk. I composed a draft of the paper under discussion here (Simmons 2016) as a return for that gift, to make good on that debt, to replace jobsearch feelings with different ones. Beyond that, more debts accrue: my ability to carry this story forward is indebted to more people than I can articulate here. The ESTS editors' invitation to write this response to commentaries by two such accomplished scholars is itself a gift, and therefore a debt.

Modern academic and achievement worlds are full of debt: student debt, debt to parents, mentors and teachers, and profound debts to the lives and labor that went into building the structures in which achievers achieve today. The achievement paradigm, as I describe it (Simmons 2016), fails to recognize historical debts. Psychological studies of achievement appear to miss the importance of debt entirely, assuming that achievement is a pure result of culture and affect orientation. Most glaringly absent is the extraction of human life and labor through slavery and wage exploitation. Psychologist David McClelland, author of The Achievement Society, makes only one gesture toward the importance of historical debts. In an odd digression, McClelland notes that both slavers and slaves have low achievement motivation. He ascribes this to relations of privilege and obedience, orientations that are passed down over generations and last long after abolition (McClelland 1961, 376-377). 
What would it mean to practice repair as reparation, as a form of making good on historical debts? Debts tell the story of past borrowings, extractions and damages. To make good on debts means to calculate, tally, account for historically, to take responsibility. In order to account, we must assess the damage, the inheritance, the broken world. Debts must be made whole. But sometimes accounts of what is wrong can themselves become part of the problem. Public accounting of damages can become absolutions, a way to conserve existing relations of domination (Ahmed 2016b). Morawksi's worry reappears, and the cure risks reproducing damage.

\section{Already Broken Worlds}

Murphy wonders, how to dwell in already broken worlds, where many people find no place to live? How might we bring an "unevenly shared condition of labor and study into our objects of care" (Murphy 2016, 130)? This, too, is a question of what to do about damage. I find myself living with an irony: while in my writing I reject a curative-therapeutic stance, in my academic practice I find myself adopting an increasingly therapeutic role. Like so many academic departments, mine has a shattered history. Fragments of fear, anger and bitterness have accumulated over decades. Stories run about past abuses, carried out by people no longer present; these are broken stories, told in fragments, diffracted through time and personal investments. Navigating through stress and conflict, I end up trying to place myself in the position of mediator, listener, therapist. I want to repair injury, damage and breakage. I want to cure, even as I know that cures sometimes end up reproducing damage.

Are there alternatives to the therapeutic stance? The combatant? The isolationist? The willfully naive? The universalist? The bureaucrat? The killjoy?

The question becomes very practical--or, rather, political: Does one stay or leave? Consult widely and promiscuously or protect the privacy of one's inner world? Bond in friendship or keep one's distance? Serve the collective, or the self? Work to build collaborative structures and standards, or try to carve out and shelter a tiny and unobtrusive space for one's own projects? These questions point to "the political stakes of affective entanglements" as researchers and as participants in high-achievement worlds (Murphy 2016, 130).

Murphy and Morawski suggest that anxiety can be politically productive. Murphy illuminates Fanon's insight that pessimism, fear and anger are "politically, ethically and theoretically generative" (130). This is particularly true for epistemological anxieties, uncertainty about the social production of truth value, which Morawski elsewhere calls "epistemological dizziness" (Morawski 2015).

Epistemological anxieties pervaded the field of experimental psychology in the 1950s1960s. Anxieties arose over the "excesses" of the psychological experiment. Intentional and nonintentional manipulations, biases and assumptions appeared to infuse the lives of both experimenters and subjects, disrupting and inflecting the experiment and its apparent results. Morawski suggests that these anxieties "opened a space" of possibility for new experimental relationships to emerge. Experimenters' preconceptions were understood to constitute the 
identity of the subjects, and vice versa. The hierarchies and spheres of action that had defined these experimental roles began to blur. The very separation between subject and experimenter came into question. Epistemological anxieties created openings for "political-ontological transformations," new configurations and relationships (Morawski 2015, 597).

Where does this all begin and end? Epistemological dizziness implies a kind of disorientation, uncertainty around where one stands and where are the limits. Sara Ahmed enjoins us to "hesitate, to tamper [sic] the strength of our tendencies with doubt" because "there is no guarantee that in struggling for justice we ourselves will be just." Doubt, anxiety and dizziness, it seems, are good to live in. "To lose confidence is the gift of a new thought" (Ahmed 2016a).

Like Murphy, I wonder, "what might non-innocent reassemblies look like? What experiments in reassembly are already happening? " (Murphy 2016, 131). Morawski encourages us to attend to the remainders, the residues, the fragments of shattered histories, histories of the leftovers, small counter-worlds that have come in and out of existence. Each of these contains its own anxieties, reproductions, slippages, tacks and toggles. To return to the opening question, "then what?" Both Murphy and Morawski offer hints of possibility.

\section{References}

Ahmed, S. 2016a. "Losing Confidence." Feminist Killjoys. Accessed July 11, 2016. https: / feministkilljoys.com/2016/03/01/losing-confidence/.

Ahmed, S. 2016b. "Progressive Racism." Feminist Killjoys. Accessed July 11, 2016. https: / feministkilljoys.com/2016/05/30/ progressive-racism/.

McClelland, D. C. 1961. The Achieving Society. Free Press MacMillan.

Morawski, J. G. 2015. “Epistemological Dizziness in the Psychology Laboratory: Lively Subjects, Anxious Experimenters, and Experimental Relations, 1950-1970." Isis 106 (3): 567-97.

Morawski, J. G. 2016. "The Challenges for Us Psychologized Moderns: A Commentary on Dana Simmons' 'Imposter Syndrome, a Reparative History.'” Engaging Science, Technology and Society 2: 132-39. DOI:10.17351/ests2016.96

Murphy, M. 2016. “Toward Non-Innocent Reassemblies: A Commentary on Dana Simmons' 'Imposter Syndrome, a Reparative History.'” Engaging Science, Technology and Society 2: 128-31. DOI:10.17351/ ests2016.94

Simmons, D. 2016. "Impostor Syndrome, a Reparative History." Engaging Science, Technology, and Society 2: 106-127. DOI:10.17351/ ests2016.33 